\title{
Producción y calidad del forraje de tres variedades de yuca bajo tres densidades de siembra
}

\section{Fodder production and quality of three cassava varieties under three planting densities}

\author{
Willian R. Gómez ${ }^{1 *}$, Carlos E. Cardona² ${ }^{2}$ Sandra T. Rivero ${ }^{3}$ \\ Recibido para publicación: Julio 28 de 2016 - Aceptado para publicación: Octubre 13 de 2016
}

\begin{abstract}
RESUMEN
Una limitante de la ganadería, de la región Caribe colombiana es la disminución de la producción y calidad del forraje en épocas de sequía o de lluvias. El objetivo del estudio fue evaluar la producción y calidad del forraje de tres variedades de yuca (SM 2546-40, SM 1511-6 y SM 2081-34) bajo tres densidades de siembra $(40.000,55.000$ y 70.000 plantas/ha) y tres edades de cosecha $(75,90$ y 105 días). El experimento se realizó en el Centro de Investigación Turipaná-Corpoica, en 2011, bajo un diseño de parcelas subdivididas, con tres repeticiones. Se evaluaron las producciones de forraje verde (PFV), materia seca (PMS), proteína bruta (PPB), contenido de proteína bruta $(\mathrm{CPB})$, fibra detergente neutro (FDN), fibra detergente acida (FDA) y cenizas. En el periodo húmedo (mayo-agosto), la PFV y PMS fue $150 \%$ más alta que en el seco (enero-abril) y, la de proteína 100\% mayor. La variedad de yuca SM 2081 34 produjo mayores PFV y PMS, y menor contenido de FDA. En las tres densidades de siembra las PFV y PMS fueron similares, pero con 55.000 y 70.000 plantas/ha, la PPB fue más alta. A los 105 días, se obtuvieron mayores PFV, PMS y PPB; mientras que, a los 75 días, el forraje presentó menores contenidos de FDN y FDA, y mayor contenido de proteína (CPB). A los 105 días, el contenido de cenizas fue más alto. La variedad SM 2081-34 produjo más materia seca y proteína a los 105 días con 55.000 plantas/ha.
\end{abstract}

Palabras clave: Yuca forrajera, materia seca, proteína bruta, fibra detergente ácida.

\begin{abstract}
One limitation of livestock farming in the Colombian Caribbean is the decline in production and quality of forage in times of drought or rain. The aim of this study was to evaluate forage production and nutritional quality of three varieties of cassava (SM 2546-40, SM 1511-6 and SM 2081-34) under three planting densities $(40,000,55,000$ and 70,000 plants ha $\left.^{-1}\right)$ and three harvest ages (75, 90 and 105 days). The experiment was conducted at the Research Center Turipaná-Corpoica, in 2011, under a splitsplit-plot design with three replications. Green fodder production (GFP), dry matter production (DMP), crude protein production (CPP), crude protein content (CPC), neutral detergent fiber (NDF), acid detergent fiber (ADF) and ash were evaluated. In the wet season (May-August), the GFP and DMP was $150 \%$ higher than in the dry season (January to April) and the protein $100 \%$ higher. Cassava variety SM 2081-34 produced greater GFP and DMP, and lower content of ADF. In the three planting densities, GFP and DMP were similar, but with 55,000 and 700,000 plants / ha, the CPP was higher. After 105 days, the highest GFP, DMP and CPP were obtained, whereas at 75 days, the forage had lower contents of NDF and ADF, and higher protein content (CPB). After 105 days, the ash content was higher. SM 2081-34 variety produced more dry matter and protein at 105 days with 55,000 ha-1 plants.
\end{abstract}

Key words: cassava forage, dry matter, crude protein, acid detergent fiber.

\footnotetext{
1* M.Sc. Investigador Corpoica-Turipaná, km 13 Vía Montería -Cereté, Córdoba, Colombia. Celular: 3216978096, wgomez@corpoica. org.co.

2 Ph.D. Profesor Titular. Universidad de Córdoba, Montería, Córdoba, Colombia.

${ }^{3}$ M.Sc. Investigador Corpoica-Tibaitatá, Mosquera, Cundinamarca, Colombia.
} 


\section{INTRODUCCIÓN}

Una de las principales limitantes que presenta la ganadería de la región Caribe es la baja producción de forraje ocasionada por la variabilidad climática, manifestada en periodos concentrados de lluvia o, en su defecto, periodos de prolongada sequía que, en muchos casos, es mayor a tres meses (Rivero et al. 2015). Estos eventos reducen en forma dramática la producción y la calidad del forraje, constituyéndose en la principal causa de los bajos índices zootécnicos de la ganadería regional, tales como producciones de carne menores a $300 \mathrm{~kg} \mathrm{ha}^{-1}$ año y edad al sacrificio mayor a tres años (Pérez-García et al. 1998), baja producción de leche por lactancia (800 - 1,14 L/vaca) e intervalos largos entre partos (420-470 días). Esta baja productividad animal repercute negativamente en la generación de ingresos de los productores (Cajas et al. 2012), y hace ineficiente el sistema de producción.

La utilización de cultivos forrajeros alternativos, que compensen el déficit de disponibilidad y calidad de los pastos durante las épocas críticas, es parte de la solución para aumentar la productividad de la ganadería bovina y así, mejorar su rentabilidad. En esta dirección, la yuca, por su potencial como cultivo forrajero puede integrarse en los sistemas de producción agropecuarios de la región Caribe colombiana. Este cultivo tiene muchas cualidades, entre las cuales, su tolerancia, a periodos de sequía de más de tres meses (El-Sharkawy 2004), altas temperaturas, condiciones de baja fertilidad (Howeler 2002) y capacidad de producción de biomasa (Bolívar y Molina 2007; Paternina 2006).

A pesar de las múltiples ventajas que se reportan para la yuca, su uso como forraje en la alimentación animal, no se ha generalizado (Bolívar y Molina 2007). Lo anterior puede deberse a que no ha habido una gran difusión de variedades de yuca seleccionadas para la producción de follaje.
Este trabajo tuvo como objetivo determinar la producción de forraje en los periodos seco y Iluvioso, y la calidad nutricional en el periodo lluvioso, en tres variedades de yuca forrajera, bajo tres densidades de siembra y tres edades de cosecha.

\section{MATERIALES Y MÉTODOS}

El experimento se desarrolló en el centro de investigación Turipaná, adscrito a la Corporación Colombiana de Investigación Agropecuaria (CORPOICA), localizado en Cereté, Córdoba, Colombia, con coordenadas $8^{\circ} 50^{\prime} 59^{\prime \prime} \mathrm{N}$ y $75^{\circ} 49^{\prime} 07^{\prime \prime} \mathrm{W}$, temperatura promedio de $28^{\circ} \mathrm{C}$, humedad relativa promedio del $81 \%$, altura sobre el nivel del mar de 20 m.s.n.m. y precipitación anual de $1.240 \mathrm{~mm}$. El área pertenece a la zona climática cálidomoderada, a la formación Bosque Seco Tropical (BS-T), zona agroecológica Cj (Palencia et al. 2006). El suelo donde se instaló el ensayo presentó textura franco-limosa, $\mathrm{pH}=6,32 ; \mathrm{MO}$ $=2,06 \% ; \mathrm{P}=26,4 \mathrm{ppm} ; \mathrm{Ca}^{2+}=13,5 \mathrm{mg} / 100 \mathrm{~g}$; $\mathrm{Mg}^{2+}=9,0 \mathrm{mg} / 100 \mathrm{~g} ; \mathrm{K}^{+}=0,99 \mathrm{mg} / 100 \mathrm{~g} ; \mathrm{ClC}$ $=23,6 \mathrm{meq} / 100 \mathrm{~g}$ de suelo.

Establecimiento del experimento. El suelo se preparó con un pase de cincel y un pase de rastra. Los esquejes empleados en la siembra fueron obtenidos de plantas sanas, con edad aproximada de 18 meses (maduras) y sembradas al día siguiente de la cosecha. Se uniformizó el material de siembra con la utilización de esquejes del tercio medio de la planta, de 20 $\mathrm{cm}$ de longitud y 2 a $3 \mathrm{~cm}$ de diámetro, con 5 a 6 yemas cada una. Las densidades de siembra se obtuvieron con una distancia fija entre calles de $1,0 \mathrm{~m}$ y distancias entre plantas de 0,25 $\mathrm{cm} ; 0,18 \mathrm{~cm}$ y $0,14 \mathrm{~cm}$, respectivamente. Se aplicó riego durante 30 días para garantizar el prendimiento y brotación de los esquejes. Se efectuaron tres controles de malezas en forma manual y no se aplicó fertilizantes. 
Los tratamientos fueron distribuidos en un diseño experimental de bloques completos al azar, con arreglo en parcelas subdivididas, y tres repeticiones. La parcela principal correspondió al factor A: variedad de yuca forrajera (SM 254640, SM 1511-6 y SM 2081-34), con un área de $108 \mathrm{~m}^{2}$, en la subparcela se incluyó el factor B: densidades de siembra $(40.000,55.000$ y 70.000 plantas ha-1), con un área de $36 \mathrm{~m}^{2}$ y en la sub-subparcela, el factor C: edad de cosecha (75, 90 y 105 días), con un área de 12 m². El efecto de los tratamientos sobre la producción de forraje se evaluó en dos periodos: seco, de enero a abril, y lluvioso, de mayo a agosto de 2011, mientras que la calidad nutricional se evaluó sólo en el periodo lluvioso.

El área de la parcela útil fue de $4 \mathrm{~m}^{2}$ en la subsubparcela, $12 \mathrm{~m}^{2}$ en la subparcela y $36 \mathrm{~m}^{2}$ en la parcela principal. El número plantas en la sub-subparcela útil fue de 48 en la densidad de 40.000 plantas $/ \mathrm{ha}^{-1}, 66$ en la de 55.000 plantas ha $^{-1}$ y 85 en la de 70.000 plantas ha-1.

Se midieron las siguientes variables en cada sub-subunidad experimental útil $\left(\begin{array}{lll}4 & \mathrm{~m}^{2}\end{array}\right)$ : producción de forraje verde (FV) en $\mathrm{kg} \mathrm{ha}^{-1}$ : se cortaron las dos calles centrales de cada subsubunidad experimental, a $40 \mathrm{~cm}$ de altura; producción de materia seca (MS) en $\mathrm{kg} \mathrm{ha}^{-1}$ : se pesaron muestras de $250 \mathrm{~g}$ de la parte aérea, se secaron en un horno con aire forzado, a $65^{\circ} \mathrm{C}$, durante 72 horas; producción de proteína bruta (PPB) en $\mathrm{kg} \mathrm{ha}^{-1}$ : sobre la base del porcentaje de proteína bruta.

Las variables de calidad del forraje, en porcentaje, fueron: contenido de proteína bruta (CPB), determinada por el método de Kjeldahl (AOAC 2005); fibra detergente neutra (FDN), fibra detergente ácida (FDA) y cenizas, según el método de Segura et al. (2007). Las determinaciones se hicieron por triplicado, una por cada repetición y solo se hicieron en el periodo lluvioso. Los datos se sometieron a análisis de varianza y pruebas de comparación múltiple de Tukey al 5\%. Se utilizó el paquete estadístico SAS versión 9.2 (2008).

\section{RESULTADOS Y DISCUSIÓN}

Producción de forraje verde (PFV) y materia seca (PMS). Las producciones de forraje verde (PFV) y materia seca (PMS), en el primer periodo, no presentaron diferencias significativas entre variedades ni entre densidades de siembra ( $p$ $>0,05)$, pero fue evidente el efecto de la edad de cosecha $(p \leq 0,05)$, aunque dependiente de la densidad de siembra, dada la significancia de esta interacción, por lo que el efecto de la edad de cosecha no fue el mismo en las tres densidades de siembra (Tabla 1).

En el segundo periodo, sepresentaron diferencias significativas entre variedades, evento que no ocurrió en el primer periodo, pero, tampoco hubo diferencias significativas entre densidades de siembra $y$, de manera consistente en los dos periodos, hubo diferencias significativas entre las edades de cosecha. En este periodo no se presentó interacción significativa entre densidad de siembra y edad de cosecha, lo que indica que los efectos de estos factores sobre la producción de forraje verde y materia seca, son independientes. La disponibilidad promedio de forraje verde fue $140,3 \%$ más alta que en el primer periodo (Tabla 1 ).

La producción de materias seca, en el segundo periodo, fue superior en $144,8 \%$ a la del primer corte (Tabla 1), resultado que reafirma la importancia del agua en el cultivo de la yuca forrajera. En términos generales la PMS se expresó de manera similar a la PFV, variables que están íntimamente ligadas (Rosero 2002).

En los dos periodos, PFV y PMS, presentaron promedios diferentes en las tres edades de cosecha, con las mayores producciones a los 105 días. En el primer periodo, la producción de forraje verde aumentó 94,5\%, en el intervalo de 75 a 90 d; 79,5\%, entre 90 y 105 días, y 
249,2\%, entre 75 y 105 días. En el segundo, los incrementos fueron menores, con $34,9 \%$, $30,8 \%$, y $76,5 \%$, respectivamente, en los mismos intervalos (Tabla 2). Estos efectos coinciden con los reportados por Bolívar y Molina (2007), quienes evaluaron la edad de cosecha en la variedad de yuca CG 11411 y encontraron que en la medida en que aumenta la edad de cosecha se alcanzan mayores producciones de forraje verde, por el alargamiento del ciclo vegetativo. No obstante, Paternina (2006) con la variedad 'venezolana' en tres edades de cosecha, 80, 90 y 100 días, no encontró diferencias.

En materia seca, los incrementos fueron $103,1 \%, 79,5 \%$ y $264,4 \%$, en el primer periodo, y en el segundo, de $32,9 \%, 37,1 \%$ y $82,2 \%$, respectivamente, en los intervalos de 75 a $90 \mathrm{~d}$, 90 a 105 d y 75 a 105 días. Resultados similares fueron reportados por Bolívar y Molina (2007), quienes encontraron aumentos a los 105 días, con respecto a 75 días. De manera similar, Paternina (2006) encontró aumentos en la producción de materia seca en la variedad de yuca 'venezolana' cuando aumentó la edad de cosecha de 90 a 100 días.

Los mayores incrementos porcentuales tanto en forraje verde como materia seca, entre las edades de cosecha, durante la época seca (primer periodo), obedece a que en la medida que se alarga el periodo de crecimiento, las plantas pudieron acceder a una mayor cantidad de agua aprovechable (Ipaz et al. 2010) en las capas más profundas del suelo, con lo cual se incrementa la transpiración y la eficiencia de transpiración. Durante la época Iluviosa la disponibilidad de agua en las capas superiores del suelo fue relativamente constante, por lo que las diferencias en las tasas de crecimiento entre las edades de cosecha fueron menores.

En el segundo periodo, con un ambiente más favorable en cuanto a cantidad de agua precipitada (Figura 1), se presentaron diferencias significativas en PFV, entre las variedades SM 2081-34 y SM 2546-40. La variedad SM 208134 superó en 35,9\% a la variedad SM 2546-40 (Tabla 2).

La densidad de siembra no tuvo efectos significativos en la PFV ni en la PMS en los dos periodos, por lo que la producción de forraje verde y materia seca fue similar (Tabla 1), lo que concuerda con lo reportado por Ipaz et al. (2010) y Paternina (2006) quienes no encontraron diferencias significativas entre densidades de siembra de 40.000 a 100.000 plantas/ha.

Por otro lado, en el segundo periodo, la variedad SM 2081-34 superó en PMS (35,9\% más) a la variedad SM 2546-40, aunque estadísticamente resultó similar a SM 1511-6 (Tabla 1).

En general, la PMS en las tres variedades, fue superior a la de las evaluadas por Rosero (2002) y Paternina (2006), a la edad de cosecha de 90 días y 40.000 plantas ha ${ }^{-1}$. No obstante, Bolívar y Molina (2007) encontraron rendimientos más altos con 109.733 plantas ha-1 y fertilización convencional.

En el primer período, el análisis de la interacción densidad de siembra vs edad de cosecha (Tabla 2), indica que, para PFV y PMS, con 40.000 plantas/ha, no hubo diferencias entre 75 y 90 días, mientras que, a los 105 días, se cosechó la mayor cantidad de forraje. Con 55.000 plantas ha $^{-1}$, las producciones de forraje a los 90 y 105 días fueron similares y superaron a la de 75 días, mientras que con 70.000 plantas $\mathrm{ha}^{-1}$, las producciones fueron diferentes en las tres edades de cosecha, con mayor magnitud también a los 105 días. Estos resultados sugieren que cuando se siembra en época de bajas precipitaciones, se debe cosechar forraje a los 105 días, bajo cualquiera de las tres densidades de siembra, pero, es preferible la densidad de 40.000 plantas/ha, ante la no significancia del efecto principal de la densidad de siembra. 


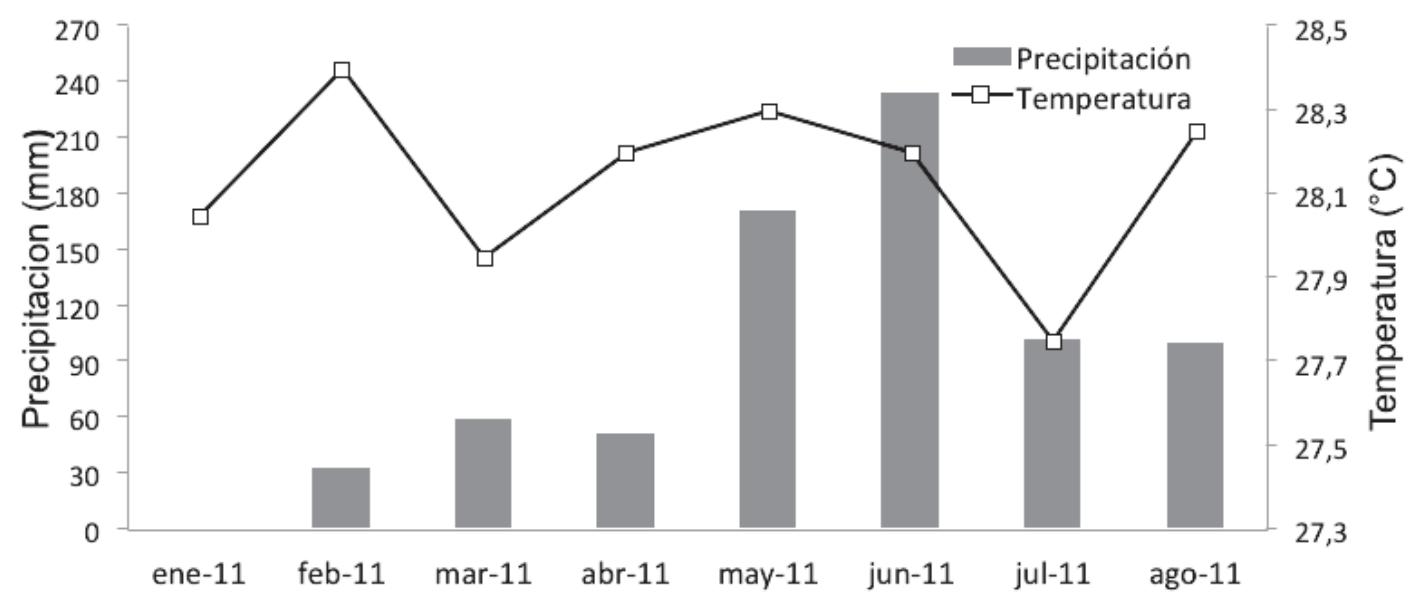

Figura 1. Medias mensuales de precipitación y humedad relativa en el primer y segundo periodo del ensayo (enero a septiembre 2011) en el C.I. Turipaná, municipio de Cereté, Córdoba. Estación meteorológica. IDEAM. Centro de Investigación Turipaná.

El período de bajas precipitaciones (enero-abril) tuvo influencia en la producción de forraje en cada densidad de siembra, dependiente de la edad de cosecha, mientras que, en el periodo de altas precipitaciones (mayo-agosto), las diferencias entre dos edades de cosecha, fueron aproximadamente constantes en todas las densidades de siembra, posiblemente porque la mayor disponibilidad de agua en el suelo, pudo influir, similarmente, en las comunidades de plantas de las tres densidades de siembra, generando mayor biomasa al aumentar la edad de cosecha, y, explicaría la significancia del factor edad de cosecha.

Producción de proteína bruta (PPB). La producción de proteína bruta fue $52,6 \%$ más alta, en el segundo periodo (Tabla 1). En el primer periodo, no hubo diferencias entre variedades, ni entre densidades de siembra, similar a lo ocurrido con PFV y PMS. Sin embargo, la edad de cosecha y la interacción densidad de siembra vs edad de cosecha, resultaron altamente significativas $(p \leq 0,05)$.

En el segundo período, tampoco hubo diferencias entre variedades, aunque entre densidades de siembra y entre edades de cosecha, las diferencias fueron significativas $(p \leq 0,05)$. En ambos periodos, la producción de proteína bruta presentó promedios diferentes en las tres edades de cosecha, con las mayores producciones a los 105 días (Tabla 1).

En el primer período, la PPB aumentó 75,8\% en el intervalo de 75 a 90 días; 91,9\% entre 90 y 105 días, y 237,2\% entre 75 y 105 días. La interacción significativa densidad de siembra vs edad de cosecha (Tabla 2), indica que, para PFV y PMS, las diferencias entre edades de cosecha fueron diferentes en las tres densidades de siembra, pero la mayor diferencia ocurrió a los 105 días. Esto sugiere que, para los materiales de yuca evaluados, cuando se siembra en épocas de bajas precipitaciones, es mejor cosechar forraje a los 105 días y utilizar la densidad de 40.000 plantas/ha.

En el segundo período, la PPB aumentó 29,9\% entre 75 y 105 días, y 34,3\% entre 90 y 105 días (Tabla 1); las mayores PPB se obtuvieron con 55.000 y 70.000 plantas/ha, y la menor, con 40.000 plantas/ha. Resultados similares fueron reportados por Ventura y Pulgar (1990), quienes encontraron diferencias al aumentar la densidad, de 20.000 a 40.000 plantas/ha. En este 
Tabla 1. Valores medios de producción de forraje verde (PFV), materia seca (PMS) y proteína bruta (PPB) de tres variedades de yuca forrajera, bajo tres densidades de siembra y tres edades de cosecha, en dos periodos del año 2011, en Corpoica-Turipaná.

\begin{tabular}{crrrrrc}
\hline Factores y niveles & \multicolumn{2}{c}{ PFV (kg/ha) } & \multicolumn{2}{c}{ PFV (kg/ha) } & \multicolumn{2}{c}{ PFV (kg/ha) } \\
\multicolumn{1}{c}{ Variedad } & \multicolumn{1}{c}{ P1 } & \multicolumn{1}{c}{ P2 } & \multicolumn{1}{c}{ P1 } & \multicolumn{1}{c}{ P2 } & P1 & P2 \\
\hline SM 2546-40 & $8.688 \mathrm{a}$ & $21.498 \mathrm{~b}$ & $1.882,0 \mathrm{a}$ & $4.660,8 \mathrm{~b}$ & $445,76 \mathrm{a}$ & $760,37 \mathrm{a}$ \\
SM 1511-6 & $9.666 \mathrm{a}$ & $24.728 \mathrm{ab}$ & $2.134,3 \mathrm{a}$ & $5.275,8 \mathrm{ab}$ & $530,05 \mathrm{a}$ & $766,35 \mathrm{a}$ \\
SM 2081-34 & $13.038 \mathrm{a}$ & $29.213 \mathrm{a}$ & $2.651,3 \mathrm{a}$ & $6.384,3 \mathrm{a}$ & $614,13 \mathrm{a}$ & $900,04 \mathrm{a}$ \\
Densidad de siembra (DS) & & & & & & \\
40.000 plantas /ha & $10.405 \mathrm{a}$ & $24.107 \mathrm{a}$ & $2.231,6 \mathrm{a}$ & $5.238,8 \mathrm{a}$ & $544,64 \mathrm{a}$ & $745,41 \mathrm{~b}$ \\
55.000 plantas/ha & $9.825 \mathrm{a}$ & $25.359 \mathrm{a}$ & $2.114,3 \mathrm{a}$ & $5.528,7 \mathrm{a}$ & $500,10 \mathrm{a}$ & $874,41 \mathrm{a}$ \\
70.000 plantas/ha & $11.161 \mathrm{a}$ & $25.972 \mathrm{a}$ & $2.321,7 \mathrm{a}$ & $5.553,4 \mathrm{a}$ & $545,20 \mathrm{a}$ & $806,95 \mathrm{a}$ \\
Edad de cosecha (EC) & & & & & & \\
75 d & $4.877 \mathrm{c}$ & $18.337 \mathrm{c}$ & $998,9 \mathrm{c}$ & $3.932,3 \mathrm{c}$ & $259,39 \mathrm{c}$ & $743,17 \mathrm{~b}$ \\
90 d & $9.485 \mathrm{~b}$ & $24.741 \mathrm{~b}$ & $2.028,5 \mathrm{~b}$ & $5.226,0 \mathrm{~b}$ & $455,90 \mathrm{~b}$ & $718,47 \mathrm{~b}$ \\
105 d & $17.030 \mathrm{a}$ & $32.361 \mathrm{a}$ & $3.640,3 \mathrm{a}$ & $7.162,7 \mathrm{a}$ & $874,65 \mathrm{a}$ & $965,13 \mathrm{a}$ \\
Promedio general & $10.463,80$ & $25.146,30$ & $2.222,50$ & $5.440,30$ & 529,98 & 808,92 \\
CV (\%) & 37,85 & 25,83 & 39,29 & 25,33 & 39,87 & 25,11 \\
\hline
\end{tabular}

P1 = periodo de enero a abril de 2011; P2=periodo de mayo a septiembre de 2011. Medias con la misma letra en cada factor no difieren significativamente, según la prueba de Tukey al 5\%, comparación vertical/periodo.

Tabla 2. Medias de producción de forraje verde (PFV), materia seca (PMS) y proteína bruta (PPB), de cada edad de cosecha, en cada densidad de siembra de yuca forrajera, variedades SM 2546-40, SM 151-6 y SM 2081. Primer periodo (enero a abril). C.I. Turipaná, Cereté-Córdoba, 2011.

\begin{tabular}{|c|c|c|c|c|c|c|c|c|c|}
\hline \multirow{2}{*}{$\begin{array}{c}\text { Densidad } \\
\text { (plantas/ha) }\end{array}$} & \multicolumn{3}{|c|}{ PFV (kg/ha) } & \multicolumn{3}{|c|}{ PMS (kg/ha) } & \multicolumn{3}{|c|}{ PPB (kg/ha) } \\
\hline & $75 \mathrm{~d}$ & $90 \mathrm{~d}$ & $105 \mathrm{~d}$ & $75 \mathrm{~d}$ & $90 \mathrm{~d}$ & $105 \mathrm{~d}$ & $75 \mathrm{~d}$ & $90 \mathrm{~d}$ & $105 \mathrm{~d}$ \\
\hline 40.000 & $4.312,0 \mathrm{~b}$ & $7379,6 \quad b$ & $19522,2 \mathrm{a}$ & $884,3 \mathrm{~b}$ & $1.593,6 \mathrm{~b}$ & $4.217,0 \mathrm{a}$ & $232,9 \mathrm{c}$ & $355,7 \mathrm{~b}$ & $1.045,3 \mathrm{a}$ \\
\hline 55.000 & $4.676,5 \mathrm{~b}$ & $11.111,06 \mathrm{a}$ & $13.688,9 \mathrm{a}$ & $965,6 \mathrm{~b}$ & $2.415,8 \mathrm{a}$ & $2.961,6 \mathrm{a}$ & 249,7 b & $560,1 \mathrm{a}$ & 690,6 a \\
\hline 70.000 & $5.642,0 \mathrm{c}$ & $9.964,5 \mathrm{~b}$ & $17.877,8$ a & $1.146,7 \mathrm{c}$ & $2.076,0 \mathrm{~b}$ & $3.742,2 \mathrm{a}$ & $295,7 \mathrm{~b}$ & $451,9 \mathrm{~b}$ & $888,1 \mathrm{a}$ \\
\hline
\end{tabular}

Medias con la misma letra no difieren significativamente, según la prueba t, al 5\% de probabilidad, comparación horizontal.

periodo, esta interacción no resultó significativa, por lo que las diferencias entre dos edades de cosecha cualesquiera fueron casi iguales en las tres densidades de siembra, aunque el efecto principal, del factor edad de cosecha, indicó diferencias entre las tres edades, con mayor PPB a los 105 días. Estos rendimientos de proteína bruta son inferiores a los reportados por Ventura y Pulgar (1990), quienes al evaluar el forraje de la yuca (hojas y tallos) bajo poblaciones de $20.000 ; 40.000$ y 60.000 plantas/ha obtuvieron una producción de proteína bruta de 1.202; 1.600 y $1.653 \mathrm{~kg} \mathrm{ha}^{-1}$, respectivamente y superiores a lo reportado por Curcelli (2013) quien evaluó la producción de proteína bruta de la parte aérea de la yuca, a $\operatorname{los} 7,8,9,10,11,12$, 13,14 y 15 días después de siembra, encontrando una PPB promedio de 258,29 kg ha-1.

Contenido de proteína bruta (CPB). El análisis de varianza no detectó diferencias significativas entre variedades (V) y densidades de siembra (DS), en tanto que, para edad de cosecha (EC), y las interacciones $\mathrm{V} x \mathrm{DS}, \mathrm{V} \times \mathrm{EC}$ y DS $\times \mathrm{EC}$, se presentaron diferencias significativas $(p \leq 0,05)$.

La cosecha a los 75 días, registró mayor contenido de proteína que a los 90 y 105 días, (Tabla 3), lo cual podría deberse a la menor edad del forraje. Los forrajes tropicales en estado 
joven se caracterizan por tener mejor calidad en términos de proteína cruda, sin embargo, el contenido de agua es mayor y la disponibilidad de materia seca es menor (Rincón et al. 2008).

La interacción variedad vs densidad de siembra (Tabla 4), muestra que con 55.000 plantas/ha, la variedad SM 1511-6, presentó mayor contenido de proteína, mientras que, para las variedades SM 2546-40 y SM 2081-34, el efecto de las tres densidades de siembra fue similar.

Al examinar la interacción variedad $\mathrm{x}$ edad de cosecha (Tabla 4), se observó que las tres variedades deyuca produjeron mayor porcentaje de proteína bruta, a los 75 días, mientras que, a los 90 y 105 días, el porcentaje de proteína permaneció constante en las tres variedades. Esto sugiere que los tres materiales difieren en la acumulación de proteína en función de la edad de cosecha, pero, en general, disminuye al alargarse el tiempo de cosecha.

Por otro lado, al analizar la interacción densidad de siembra vs edad de cosecha (Tabla 5), se observó que el mayor porcentaje de proteína bruta del forraje en las tres densidades de siembra se expresó a los 75 días de cosecha, mientras que, a los 90 y 105 días, el porcentaje de proteína fue similar en las tres densidades

Tabla 3. Medias de porcentaje de proteína bruta (CPB), fibra detergente neutra (FDN), fibra detergente ácida (FDA) y cenizas, de tres variedades de yuca, bajo tres densidades de siembra y tres edades de cosecha. C.I. Turipaná, Cereté-Córdoba, 2011.

\begin{tabular}{lrrrr}
\hline \multicolumn{1}{c}{ Factores y niveles } & CPB & FDN & FDA & CENIZAS \\
\hline Variedad & & & & \\
SM 2546-40 & $20,1 \mathrm{a}$ & $46,9 \mathrm{a}$ & $29,4 \mathrm{a}$ & $7,7 \mathrm{a}$ \\
SM 1511-6 & $20,5 \mathrm{a}$ & $45,9 \mathrm{a}$ & $27,4 \mathrm{ab}$ & $7,5 \mathrm{a}$ \\
SM 2081-34 & $20,3 \mathrm{a}$ & $45,2 \mathrm{a}$ & $26,9 \mathrm{~b}$ & $7,5 \mathrm{a}$ \\
Densidad de siembra (DS) & & & & \\
$\quad$ 40.000 plantas /ha & $20,3 \mathrm{a}$ & $45,3 \mathrm{a}$ & $27,9 \mathrm{a}$ & $7,7 \mathrm{a}$ \\
55.000 plantas/ha & $20,3 \mathrm{a}$ & $47,7 \mathrm{~b}$ & $28,2 \mathrm{a}$ & $7,5 \mathrm{a}$ \\
70.000 plantas/ha & $20,1 \mathrm{a}$ & $45,1 \mathrm{a}$ & $27,6 \mathrm{a}$ & $7,5 \mathrm{a}$ \\
Edad de cosecha (EC) & & & & \\
75 días & $22,4 \mathrm{a}$ & $43,4 \mathrm{~b}$ & $25,5 \mathrm{c}$ & $7,4 \mathrm{~b}$ \\
$\quad$ 90 días & $19,3 \mathrm{~b}$ & $44,6 \mathrm{~b}$ & $27,9 \mathrm{~b}$ & $7,1 \mathrm{~b}$ \\
105 días & $19,1 \mathrm{~b}$ & $50,1 \mathrm{a}$ & $30,3 \mathrm{a}$ & $8,1 \mathrm{a}$ \\
Promedio general & 20,26 & 46,03 & 27,89 & 7,55 \\
$\quad$ DE & 1,30 & 4,96 & 2,96 & 0,54 \\
\hline
\end{tabular}

Medias con la misma letra en cada factor no difieren significativamente, según la prueba de Tukey al 5\% de probabilidad. DE=desviación estándar.

Tabla 4. Medias del porcentaje de proteína bruta (CPB) en cada densidad de siembra y edad de cosecha por variedad y, de fibra detergente ácida (FDA) en cada densidad de siembra por variedad. Primer periodo (enero a abril). C.I. Turipaná, Cereté-Córdoba, 2011.

\begin{tabular}{lrrrrrrrrr}
\hline Variedad & \multicolumn{9}{c}{ CPB } \\
& $\mathbf{4 0 . 0 0 0}$ & $\mathbf{5 5 . 0 0 0}$ & $\mathbf{7 0 . 0 0 0}$ & $\mathbf{4 0 . 0 0 0}$ & $\mathbf{5 5 . 0 0 0}$ & $\mathbf{7 0 . 0 0 0}$ & $\mathbf{7 5 ~ d}$ & $\mathbf{9 0 ~ d}$ & $\mathbf{1 0 5} \mathbf{d}$ \\
\hline SM 2546-40 & $20,4 \mathrm{a}$ & $19,2 \mathrm{a}$ & $20,7 \mathrm{a}$ & $30,1 \mathrm{a}$ & $29,9 \mathrm{a}$ & $28,0 \mathrm{a}$ & $21,4 \mathrm{a}$ & $19,2 \mathrm{~b}$ & $19,7 \mathrm{~b}$ \\
SM 1511-6 & $20,3 \mathrm{~b}$ & $21,5 \mathrm{a}$ & $19,6 \mathrm{~b}$ & $26,0 \mathrm{~b}$ & $25,9 \mathrm{~b}$ & $30,3 \mathrm{a}$ & $23,3 \mathrm{a}$ & $19,4 \mathrm{~b}$ & $18,6 \mathrm{~b}$ \\
SM 2081-34 & $20,4 \mathrm{a}$ & $20,3 \mathrm{a}$ & $20,1 \mathrm{a}$ & $27,5 \mathrm{ab}$ & $28,7 \mathrm{a}$ & $24,5 \mathrm{~b}$ & $22,4 \mathrm{a}$ & $19,3 \mathrm{~b}$ & $19,1 \mathrm{~b}$ \\
\hline
\end{tabular}

Medias con la misma letra no difieren significativamente, según la prueba t al 5\% de probabilidad, comparación horizontal. 
Tabla 5. Medias del porcentaje de proteína bruta (PB), fibra detergente ácida (FDA) y cenizas, de cada edad de cosecha, en cada densidad de siembra de yuca forrajera, variedades SM 2546-40, SM 151-6 y SM 2081. Primer periodo (enero a abril). C.I. Turipaná, Cereté-Córdoba, 2011.

\begin{tabular}{lccccccccc}
\hline $\begin{array}{c}\text { Densidad } \\
\text { (plantas/ha) }\end{array}$ & $\mathbf{7 5 ~ d ~}$ & $\mathbf{9 0 ~ d}$ & $\mathbf{1 0 5} \mathbf{~ d}$ & $\mathbf{7 5 ~ d}$ & $\mathbf{9 0 ~ d}$ & $\mathbf{1 0 5} \mathbf{d}$ & $\mathbf{7 5 ~ d}$ & $\mathbf{9 0 ~ d}$ & $\mathbf{1 0 5} \mathbf{~ d}$ \\
\hline 40.000 & $23,1 \mathrm{a}$ & $19,4 \mathrm{~b}$ & $18,6 \mathrm{~b}$ & $23,8 \mathrm{~b}$ & $28,9 \mathrm{a}$ & $30,9 \mathrm{a}$ & $7,3 \mathrm{~b}$ & $7,2 \mathrm{~b}$ & $8,5 \mathrm{a}$ \\
55.000 & $22,3 \mathrm{a}$ & $19,9 \mathrm{~b}$ & $18,7 \mathrm{~b}$ & $24,7 \mathrm{~b}$ & $28,2 \mathrm{ab}$ & $31,7 \mathrm{a}$ & $7,6 \mathrm{ab}$ & $6,9 \mathrm{~b}$ & $8,0 \mathrm{a}$ \\
70.000 & $21,8 \mathrm{a}$ & $18,7 \mathrm{~b}$ & $20,0 \mathrm{~b}$ & $28,0 \mathrm{a}$ & $26,7 \mathrm{a}$ & $28,2 \mathrm{a}$ & $7,4 \mathrm{a}$ & $7,3 \mathrm{a}$ & $7,7 \mathrm{a}$ \\
\hline
\end{tabular}

Medias con la misma letra no difieren significativamente, según la prueba t, al 5\% de probabilidad, comparación horizontal.

de siembra. En general, el mayor porcentaje de proteína bruta se logró al cosechar a los 75 días, independientemente de la variedad y la densidad de siembra.

Los valores promedios de CPB hallados en este estudio son similares a los reportados por Dongmeza et al. (2009) quienes evaluaron la calidad nutricional de las hojas de yuca con cortes de tres meses y encontraron valores de CPB entre 20,6\% y 27,4\%. Patiño et al. (2013) encontraron $\mathrm{CPB}$ de $22,2 \%$ en ensilaje de la parte aérea de la yuca.

Fibra detergente neutra (FDN). El contenido de FDN sólo presentó diferencias significativas entre densidades de siembra y edad de cosecha (Tabla 3) y fue mayor en la densidad de siembra de 55.000 plantas/ha, mientras que no hubo diferencias significativas entre las densidades de siembra de 40.000 y 70.000 plantas/ha.

Por otro lado, el valor más alto de FDN se observó a los 105 días de cosecha, con diferencias significativas respecto a los 75 y 90 días, que a su vez resultaron similares estadísticamente entre sí. Estos promedios están dentro del rango de los hallados por Pinho et al. (2004); Quiñones et al. (2007); Nunes-Irmøo et al. (2008); Phengvilaysouk y Wanapat (2008); Ferreira et al. (2009); Dongmeza et al. (2009); Machado (2010) y Curcelli (2013) quienes evaluaron el contenido nutricional del forraje de yuca y encontraron valores de FDN entre $25,5 \%$ y $75,5 \%$.
El incremento del contenido de FDN en la planta a medida que aumenta la edad de esta, obedece a que los contenidos de celulosa, hemicelulosa y lignina que hacen parte de la pared celular, aumentan con la edad de la planta.

Fibra detergente acida (FDA). El contenido de FDA del forraje fue estadísticamente diferente entre variedades y edades de cosecha, pero fue similar entre densidades de siembra (Tabla 3). Además, se detectaron interacciones significativas entre variedad y densidad de siembra (Tabla 4) y densidad de siembra $x$ edad de cosecha (Tabla 5). El contenido de FDA, en la variedad SM 2081-34, fue significativamente menor que en la variedad SM 2546-40, lo que hace que su forraje sea potencialmente más digestible. Sin embargo, en la variedad SM 1511-6, el contenido de FDA no fue diferente significativamente de las variedades antes mencionadas.

Por otro lado, a medida que aumentó la edad de cosecha del forraje, la FDA también aumentó, con incrementos aproximadamente constantes de 2,4\% por cada 15 días de retraso de la cosecha, lo que indica una tendencia lineal en el tiempo. Este incremento constante va en contravía de la digestibilidad del forraje, y se debe, entre otros factores, a la insolubilización de los carbohidratos, a la lignificación progresiva de la pared celular y a la disminución de la disponibilidad de proteína, que combinados provocan que los animales hagan una menor degradación del forraje en el rumen (Santana et al. 2010). 
Al examinar la interacción variedad vs densidad de siembra (Tabla 4), se observó menor porcentaje de FDA en la variedad SM 1511-6, con 40.000 y 55.000 plantas/ha, mientras que en la variedad SM 2081-34, el menor porcentaje se registró con 70.000 plantas/ha. En contraste, en la variedad SM 2546-40, las distancias de siembra no tuvieron efecto diferencial sobre el porcentaje de FDA.

En la interacción densidad de siembra vs edad de cosecha (Tabla 4), se observó menor contenido de FDA cuando se cosechó a los 75 días, con las densidades de siembra de 40.000 y 55.000 plantas/ha; para estas dos densidades de siembra, a medida que aumentó la edad de cosecha del forraje de yuca, también aumentó el contenido de FDA, con la consecuente disminución de la digestibilidad del forraje. En contraste, con 70.000 plantas/ha, el contenido de FDA no varió en las tres edades de cosecha, fue relativamente constante. Es posible que, con la mayor distancia de siembra, las altas poblaciones de plantas, puedan generar una mayor cantidad de tejidos tiernos que compensen la tasa de maduración de los antes formados y mantener así constante el contenido de FDA.

Los valores de FDA, observados en este estudio, cuya media general fue $27,89 \pm 2,96$, son superiores a los reportados por Dongmeza et al. (2009), quienes hallaron valores de FDA de $18,1 \%, 21,0$ y $18,8 \%$, en follaje de yuca en tres cortes de tres meses cada uno. E inferiores a los reportados por Phengvilaysouk y Wanapat (2008) quienes hallaron valores de 30,55\% y $33,43 \%$, en forraje de yuca cortado a los 2 y 4 meses de edad, respectivamente. Asimismo, Paternina (2006) también reportó 47,0\% de FDA en forraje de la variedad 'venezolana' a una edad de 90 días y Curcelli (2013), reportó un valor promedio de FDA de 45,22\% en nueve podas con cortes mensuales. Patiño et al. (2013) y Modesto et al. (2004), hallaron valores de $32,14 \%$ y $41 \%$ respectivamente, en ensilaje de la parte aérea de la yuca; Pinho et al. (2004),
Vongsamphanh y Wanapat (2004), Carvalho et al. (2006) y Figuereido et al. (2006) 47,54\%, $33,9 \%, 28,11 \%$ y $35,99 \%$, respectivamente, en heno de forraje de yuca.

Contenido de Cenizas. Se presentaron diferencias significativas entre edades de cosecha, no hubo diferencias entre variedades ni entre densidades de siembra (Tabla 3). Similar a lo acontecido con las otras variables analizadas, la interacción densidad de siembra x edad de cosecha, resultó significativa, lo que indica que el contenido de cenizas varía según la edad de cosecha, en función de la densidad de siembra (Tabla 5). Además, la interacción de segundo orden variedad $x$ densidad de siembra $\mathrm{x}$ edad de cosecha, también resulto significativa, lo que indica que el contenido de cenizas también depende del efecto conjunto de variedad y densidad de siembra.

El mayor contenido de cenizas se produjo a los 105 días, mientras que a los 75 y 90 días no hubo diferencias significativas (Tabla 3). Este efecto principal de la edad de cosecha, no es independiente de la densidad de siembra, ya que, si bien se cumple para 40.000 plantas/ ha, con 70.000 plantas/ha no se presentan diferencias significativas entre las edades de cosecha y, con 55.000 plantas/ha, la respuesta no es consistente en cuanto a las diferencias entre 75 y 105 días, pues resultaron iguales estadísticamente (Tabla 5).

Al examinar la interacción de segundo orden, se observó que sólo en la variedad SM 2546-40 y a las densidades de 40.000 y 55,000 plantas/ ha, el contenido de cenizas fue mayor a los 105 días; en el resto de combinaciones no se encontraron diferencias significativas.

Los porcentajes de cenizas registrados en el presente estudio fueron similares a los reportados por Dongmeza et al. (2009) quienes encontraron valores entre $7,0 \%$ y $8,4 \%$. Sin embargo, Paternina (2006), en un trabajo 
similar reportó $5,8 \%$ de ceniza en la parte aérea de la yuca también cosechada a los tres meses, valor inferior al reportado en el presente estudio. Asimismo, Patiño et al. (2013) encontraron promedios de $8,82 \%$ de ceniza en ensilaje de la parte aérea de la yuca de tres meses; Vongsamphanh y Wanapat (2004) y Moretine et al. (2004) hallaron valores en el rango de $6,05 \%$ a $12,17 \%$ y, Carvalho et al. (2006) y Figueredo et al. (2006), en heno de la parte aérea de la yuca encontraron valores promedios para cenizas de $14,64 \%$ y $5,50 \%$, respectivamente.

\section{CONCLUSIONES}

En el periodo seco no hubo diferencias en producción de forraje verde, materia seca y proteína bruta, entre variedades ni entre densidades de siembra, pero fue influyente la edad de cosecha con diferencias bien marcadas entre las tres edades, con superioridad de la de 105 días.

En el período Iluvioso (mayo-agosto), las producciones de forraje verde y materia seca, fue casi $150 \%$ más alta que en el periodo seco (enero-abril) y, la de proteína bruta, casi $100 \%$ mayor; la variedad de yuca SM 208134 produjo mayor cantidad de forraje verde y materia seca; la mayor producción de proteína bruta se obtuvo con 55.000 y 70.000 plantas/ ha, independientemente de la variedad, y la edad de cosecha a los 105 fue la más productiva en los tres caracteres mencionados.

La calidad del forraje, evaluado en el periodo lluvioso, mostró contenidos porcentuales de proteína mayores en las variedades SM 254640 y SM 2081-34 a las densidades de 40.000 y 70.000 plantas/ha, y a su vez, menores contenidos de fibra detergente ácido (FDA), lo que, junto con las mayores producciones de forraje, representan una alternativa para aumentar la productividad ganadera bovina en el Caribe colombiano.

\section{REFERENCIAS}

AOAC. 2005. Official Methods of Analysis of AOAC International. $18^{\text {th }}$ Edition, Gaithersburg, Maryland 20877-2417.

Bolívar, M. y Molina, S. 2007. Evaluación agronómica de la yuca (Manihot esculenta Crantz) cultivada en el Valle del Sinú, Colombia. Livestock Research for Rural Development 19(12).

Cajas, Y., Barragán, W., Arreaza, L., Arguelles, J., Amézquita, E., Abuabara, Y., Panza, B. y Lascano, C. 2012. Efecto sobre la producción de carne de la aplicación de tecnologías de renovación de praderas de Bothriochloa pertusa (L.) A. Camus en la Costa Norte Colombiana. Revista Corpoica Ciencia y Tecnología Agropecuaria 13(2): 213-218.

Carvalho, G., Pires, A., Veloso, C., Detman, E., Silva, F. y Silva, R. 2006. Degradabilidad ruminal do feno de alguns alimentos volumosos para ruminantes. Revista Arquivo Brasileiro de Medicina Veterinária e Zootecnia 58(4): 575-580.

Curcelli, F. 2013. Épocas de poda da planta de mandioca para uso na alimenta animal. Tese doutorado. Universidade Estadual Paulista "Julio de Mesquita Filho". Botucatu-SP.

Dongmeza, E., Steinbronn, S., Francis, G., Focken, U. and Becker, K. 2009. Investigations on the nutrient and antinutrient content of typical plants used as fish feed in small scale aquaculture in the mountainous regions of Northern Vietnam. Animal Feed Science and Technology 149: 162-178.

El-Sharkawy, M. 2004. Cassava biology and physiology. Plant Molecular Biology 56: 481-501. 
Ferreira, A., Silva, A., Pereira, L., Braga, L., Moraes, S. y Araujo, G. 2009. Produção e valor nutritivo da parte aérea da mandioca, maniçoba e pornunça. Revista Brasileira de Saúde e Produção Animal 10 (1): 983-990.

Figuereido, M., Souza, L. y Ferreira, J. 2006. Cinética da degradação ruminal da materia seca da haste, da raiz, do feno da parte aérea e da silagem de raíz de mandioca (Manihot esculenta Crantz) tratada con ureia. Brazilian Journal of Veterinary Research and Animal Science 43(1):11 - 17.

Howeler, R. 2002. Cassava mineral nutrition and utilization. En: Hillocks, R., Thresh, J. and Belloti, A. (Ed). Cassava: biology, production y utilization. CABI Wallingford, p115-147.

Ipaz, C., Madero, E., Ramirez, M. y Gómez, A. 2010. Producción de forraje de yuca HMC- 1 en un Haplustoll Entico con diferentes regímenes de humedad. Acta Agronómica. 59 (2):170-179.

Machado, L. 2010. Avaliação da parte aérea de cultivares de mandioca, desempenho e digestibilidade em dietas simplificadas e semisimplificadas com ou sem suplementação enzimática para coelhos em crescimento. Tese doutorado. Universidade Federal de Minas Gerais. Belo Horizonte.

Modesto, E., Santos, G., Vilela, D., Silva, D., Faustino, J., Jobim, C., Detmann, E., Zambom, M. y Marques, J. 2004. Caracterição químico - bromatologica da silagemdo terço superior da rama de mandioca. Acta Scientarium, 26 (1): 137 146.
Moretine, C., Lima, J., Fialho, E. y Mercer, A. 2004. Avaliação nutricional de alguns alimentos para eqüinos por meio de ensaios metabólicos. Ciência e Agrotecnologia 28 (3): 621 -626.

Nunes-Irmão, J., Figueiredo, M., Pereira, L., Ferreira, J., Rech, J. y Oliveira, B. 2008. Composição química do feno da parte aérea da mandioca em diferentes idades de corte. Revista Brasileira de Saúde e Produção Animal 9(1): 158-169.

Palencia, g., Mercado, T. y Combatt, E. 2006. Estudio agroclimático del departamento de Córdoba. Ed. Graficas el Caribe, Montería. p126.

Paternina, Y. 2006. Efectos de la densidad de siembra sobre los parámetros de producción forrajera y el valor nutritivo de la variedad venezolana (Manihot esculenta Crantz) en el municipio de Sahagún- Córdoba. Tesis Zootecnista, Universidad de Sucre. Sincelejo.

Patiño, R., Romero, A., Pérez, J., Rivero, S., Salcedo, E. y Suarez, E. 2013. Calidad y aceptabilidad del ensilaje de hoja de yuca adicionado con niveles crecientes de tuza de maíz. Revista electrónica de Veterinaria 11(11B): 1-5.

Pérez-García, J., Martínez, G., Alvarado, L. y Ossa, G. 1998. Características productivas y reproductivas de fincas del sistema doble propósito en el departamento de Córdoba. Corpoica, Cereté p 24-26.

Phengvilaysouk, A. y Wanapat, M. 2008. Study on the effect of harvesting frequency on cassava foliage for cassava hay production and its nutritive value. Livestock Research for Rural Development. 20 (supplement). 
Pinho, E., Costa, C., Arrigoni, M., Silveira, A., Padovani, C. and Pinho, S. 2004. Fermentation and nutritive value of silage and hay made from the aerial part of cassava (Manihot esculenta Crantz). Scientia Agricola 6(4): 364 -370.

Quiñones, R., González, C., Polanco, D., Perdomo, B. y Araque, H. 2007. Evaluación de diferentes tipos de deshidratación de raíz y follaje de yuca amarga (Manihot esculenta Crantz) sobre su composición química. Zootecnia Tropical 25 (1): 37-41.

Rivero, S., Gómez, W., Salcedo, E., Tordecilla, L. y Ramos, E. 2015. Nuevas variedades de yuca para la alimentación animal. Corpoica, Bogotá, p7.

Rincón, A. y Ligarreto, G. 2008. Productividad de la asociación maíz-pastos en suelos ácidos del Piedemonte Llanero colombiano. Revista Corpoica Ciencia y Tecnología Agropecuaria 9 (1): 73-80.

Rosero, D. 2002. Evaluación, producción y calidad del forraje de yuca (Manihot esculenta Crantz) con corte periódico manual. Trabajo de grado Ingeniero Agrónomo. Universidad Nacional de Colombia, Palmira.
Santana, A., Pérez, A. y Figueredo, A. 2010. Efectos del estado de madurez en el valor nutritivo y momento óptimo de corte del forraje Napier (Pennisetum purpureum Schum.) en época lluviosa. Revista Mexicana de Ciencias Pecuarias 1 (3): 227-286.

SAS. 2008. User's guide SAS/STAT ${ }^{\circledR}$ version 9.2. SAS Institute, Cary, NC, USA.

Segura, F., Echeverri, R. y Patiño, C. 2007. Descripción y discusión acerca de los métodos de análisis de fibra y del valor nutricional de forrajes y alimentos para animales. Vitae 14 (1): 72-81.

Ventura, J. y Pulgar, R. 1990. Efecto de la densidad de siembra y frecuencia de corte sobre los componentes de la producción y follaje de yuca Manihot esculenta Crantz. Revista de la Facultad de Agronomía 7(4): 229-243.

Vongsamphanh, P. y Wanapat, M. 2004. Compararison of cassava hay yield and chemical composition of local and introduced varieties and effects of levels of cassava hay supplementation in native beef cattle fed on rice straw. Livestock Research for Rural Development 16 (8). 